\title{
The Impact of Hospitalization for Pneumonia
}

\author{
Gobernado $\mathrm{ML}^{*}$, Rubio $\mathrm{AP}^{1}$, Garcia EL ${ }^{1}$ and Eiros JM${ }^{1}$ \\ ${ }^{1}$ Hospital Clínico Universitario de Valladolid, Spain \\ *Corresponding author: Gobernado ML, Hospital Clinico Universitario de Valladolid, Spain, Tel: +81-43-222-7171; Fax: +81-43-226-2176; E-mail: \\ mlopezgob@saludcastillayleon.es
}

Received date: February 15, 2017; Accepted date: March 14, 2017; Published date: March 17, 2017

Copyright: @ 2017 Gobernado ML, et al. This is an open-access article distributed under the terms of the Creative Commons Attribution License, which permits unrestricted use, distribution, and reproduction in any medium, provided the original author and source are credited.

\section{Letter to Editor}

We have read with interest the article of the Group of NEUMOEXPERTOS, Rivero-Calle et al. in which they analyze the patients diagnosed in primary care with community-acquired pneumonia (CAP) in the five-year period 2009-2013, in Spain [1].

In line with their reflections, we would like to make a simple contribution derived from our work in a series of patients hospitalized for pneumonia, in the six-year period 2009-2014 in a tertiary hospital of the Spanish National Health System.

The importance of determining the burden of disease due to pneumonia is sufficiently verified [2-6]. We have realized a retrospective study in which 5,758 episodes of pneumonia have been reviewed in a Spanish tertiary hospital, which serves a population of 275,000 inhabitants.

The mean age obtained in our work is 69.34 years $( \pm 21.80$ years $)$ with a median of 77 years. The age of the patients has been treated by age groups and we observed that the number of hospitalizations increases with age, $75 \%$ of patients admitted to the hospital by CAP have been older than 62 years. Our results show that the incidence of over 65 years of age remains constant in the time series around 22 per 1000 inhabitants in men older than 65 years and 9.5 per 1000 in women older than 65 years. The period of our study shows the disaggregated incidence in age groups over fifty years old, per thousand inhabitants, hospitalized between 65 and 74 years old have an incidence of 5.37, the age group between 75 and 84 years 13.96 and those over 85 have an incidence of 23.66 per thousand inhabitants. The most frequently causative etiologic agent of pneumonia identified by us is $S$. Pneumoniae (18.04\%), followed in order of frequency by Pseudomonas (13.55\%), Haemophilus influenza (9.82\%) and gramnegative bacteria $(9.14 \%)$.

The number of comorbidities recorded in each episode of pneumonia in the six-year period we studied, has an average of 8.46 secondary diagnoses, with a higher rate in men than in women. Likewise, there have been a greater number of comorbidities in elderly patients, the prevalent being those related to some type of heart disease (38.77\%), chronic obstructive pulmonary disease and associated diseases (23.64\%), and diabetes mellitus (20.45\%).

This contribution aims to define that the burden of hospitalization for pneumonia in older adults has a major impact on health systems.
Similarly, it should be noted that, establishing an adequate health policy through a strategy of vaccination against Streptococcus pneumonia, may prove to be a sovereignly efficient choice from the cost-benefit point of view by reducing the costs of decreasing income Hospital and from the point of view of cost-effectiveness with lower rates of mortality, and in this way it is being reflected in some recent studies [7-9].

\section{References}

1. Rivero CI, Pardo SJ, Aldaz P, Vargas DA, Mascarós E, et al. (2016) Incidence and risk factor prevalence of community-acquired pneumonia in adults in primary care in Spain (NEUMO-ES-RISK project). BMC Infect Dis 16: 64.

2. Vila CA, Aguirre CC, Ochoa GO, Diego C, Rodríguez BT, Gomez F, et al. (2015) Influence of chronic illnesses and underlying risk conditions on the incidence of pneumococcal pneumonia in older adults. Infection 43: 699-706.

3. Vila CA, Ansa X, Ochoa GO, Satue E, Diego C, Rodriguez BT. Pneumococcal pneumonia in adults 60 years or older: Incidence, mortality and prevention. Med Clin(Barc) 146: 199-202.

4. Gil PR, Pascual GR, Walter S, Álvaro MA, Gil DM (2016) A risk of hospitalization due to pneumococcal disease in adults in Spain. The CORIENNE study. Hum Vaccin Immunother 12: 1900-1905.

5. Griffin MR, Zhu Y, Moore MR, Whitney CG, Grijalva CG (2013) U.S. hospitalizations for pneumonia after a decade of pneumococcal vaccination. N Engl J Med 369: 155-163.

6. Uematsu H, Kunisawa S, Yamashita K, Imanaka Y (2015) The impact of patient profiles and procedures on hospitalization costs through length of stay in community-acquired pneumonia patients based on a japanese administrative database. PLoS One 10: e0125284.

7. Baldo V, Cocchio S, Gallo T, Furlan P, Romor P, et al. (2016) Pneumococcal conjugated vaccine reduces the high mortality for community acquired pneumonia in the elderly: an italian regional experience. PLoS One 11: e0166637.

8. Werkhoven C, Hollingsworth R, Huijts S, Bolkenbaas M, Webber C, et al. (2016) Pneumococcal conjugate vaccine herd effects on non-invasive pneumococcal pneumonia in elderly. Vaccine 34: 3275-3282.

9. Georgalis L, Mozalevskis A, Martínez AMV, Garrido EM (2017) Changes in the pneumococcal disease-related hospitalisations in Spain after the replacement of 7 -valent by 13 -valent conjugate vaccine. Eur J Clin Microbiol Infect Dis 36: 575-583. 